\title{
Rapamycin increases survival in ALS mice lacking mature lymphocytes
}

\author{
Kim A Staats ${ }^{1,2,3,4}$, Sara Hernandez ${ }^{1,2}$, Susann Schönefeldt ${ }^{3,4}$, André Bento-Abreu ${ }^{1,2}$, James Dooley 3,4, \\ Philip Van Damme ${ }^{1,2,5}$, Adrian Liston ${ }^{3,4}$, Wim Robberecht ${ }^{1,2,5}$ and Ludo Van Den Bosch ${ }^{1,2^{*}}$
}

\begin{abstract}
Background: Amyotrophic Lateral Sclerosis (ALS) is a devastating progressive neurodegenerative disease. Disease pathophysiology is complex and not yet fully understood, but is proposed to include the accumulation of misfolded proteins, as aggregates are present in spinal cords from ALS patients and in ALS model organisms. Increasing autophagy is hypothesized to be protective in ALS as it removes these aggregates. Rapamycin is frequently used to increase autophagy, but is also a potent immune suppressor. To properly assess the role of rapamycin-induced autophagy, the immune suppressive role of rapamycin should be negated.
\end{abstract}

Findings: Autophagy is increased in the spinal cord of ALS mice. Dietary supplementation of rapamycin increases autophagy, but does not increase the survival of mutant SOD1 mice. To measure the effect of rapamycin in ALS independent of immunosuppression, we tested the effect of rapamycin in ALS mice deficient of mature lymphocytes. Our results show that rapamycin moderately increases the survival of these ALS mice deficient of mature lymphocytes.

Conclusions: Rapamycin could suppress protective immune responses while enhancing protective autophagy reactions during the ALS disease process. While these opposing effects can cancel each other out, the use of immunodeficient mice allows segregation of effects. Our results indicate that maximal therapeutic benefit may be achieved through the use of compounds that enhance autophagy without causing immune suppression.

Keywords: Autophagy, Rapamycin, Neurodegeneration, Amyotrophic lateral sclerosis, Motor neuron disease, Sirolimus, Rapamune, Immunosuppression

\section{Findings}

Amyotrophic Lateral Sclerosis (ALS) is a devastating progressive neurodegenerative disease, which primarily involves the loss of motor neurons and denervation of muscle fibers, resulting in muscle weakness and paralysis. The disease has an annual incidence of 2.7 cases per 100,000 people in Europe [1] and most patients succumb to the disease within 3 to 5 years after onset. On average $10 \%$ of all ALS cases are familial, of which $20 \%$ are caused by mutations in the superoxide dismutase 1 (SOD1) gene. Based on these mutations, ALS rodent models have been generated that predictably mimic the

\footnotetext{
* Correspondence: Ludo.VandenBosch@vib-kuleuven.be

'Laboratory of Neurobiology, Vesalius Research Center, VIB, Leuven, Belgium

2Experimental Neurology (Department of Neurosciences), Leuven Research Institute for Neuroscience and Disease (LIND), University of Leuven (KU

Leuven), Leuven, Belgium

Full list of author information is available at the end of the article
}

patient disease process [2]. As disease progression is indistinguishable between familial and sporadic cases, common disease mechanisms are expected. Two of these mechanisms are aggregation [3] and the impaired clearance of misfolded proteins [4].

A process to induce clearance of aggregated or misfolded proteins is macroautophagy (further described as autophagy). This is an intracellular clearance mechanism to degrade long-lived proteins and organelles. Autophagy is increased in cells expressing (mutant) ALS genes in vitro [5], in the spinal cord of ALS mice [6-8] and of ALS patients [9]. Increasing autophagy is beneficial in neurodegenerative disease models, including those for Alzheimer's disease [10], Parkinson's disease [10], spinal cerebellar ataxia 3 [11], Huntington's disease [12] and frontotemporal lobar dementia [13]. Also in ALS mice, genetically increasing autophagy in neurons increases survival [14]. Pharmacologically, increasing 


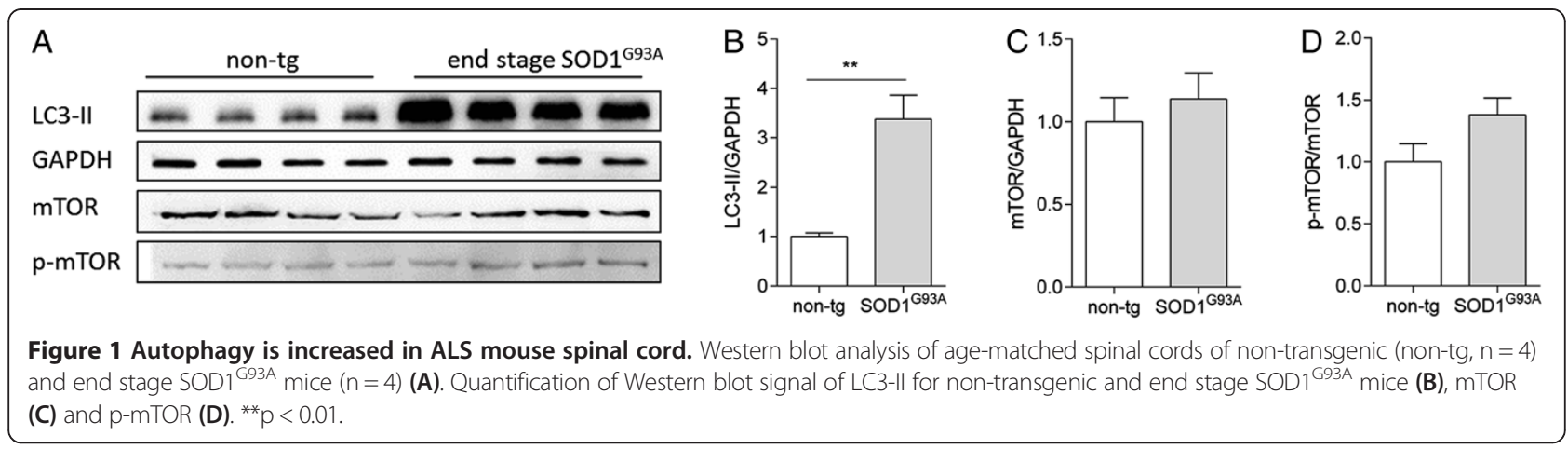

autophagy in ALS mice has not yet provided similar beneficial results.

Rapamycin is frequently used to pharmacologically increase autophagy by inhibiting the phosphorylation of the mammalian target of rapamycin (mTOR) [15]. In ALS mice, this drug has severely decreased survival [6] or did not affect survival [16]. Rapamycin is additionally used as a potent immunosuppressant as it inhibits the activation of T-cells [17]. Interestingly, removal of mature lymphocytes or functional T-cells in ALS mice decreases survival $[18,19]$ and thus rapamycin may be, in part, detrimental in ALS due to its immunosuppressive action. Dietary restriction experiments on ALS mice have shown to increase autophagy and decrease ALS mouse survival [20]. These studies may also be influenced by immunosuppression as dietary restriction also decreases activation of mTOR [21].

To confirm whether autophagy is increased in SOD $1^{\text {G93A }}$ mice, we performed Western blot analysis. The lipid-bound form of microtubule-associated proteins $1 \mathrm{~A} / 1 \mathrm{~B}$ light chain (LC3-II) is increased in the spinal cord of end stage SOD $1^{\text {G93A }}$ compared to agematched non-transgenic mice (Figure $1 \mathrm{~A} \& \mathrm{~B}$ ). $\mathrm{mTOR}$ is similarly expressed at end stage (Figure $1 \mathrm{~A} \& \mathrm{C}$ ) as is the phosphorylation of this receptor (Figure 1A \& D).

Next, we confirmed that dietary supplementation of rapamycin increases autophagy. Increased levels of LC3-II are detected in spinal cords of $\mathrm{RAG}^{-/-}$mice treated with rapamycin (Figure $2 \mathrm{~B}$ ). The expression of $\mathrm{mTOR}$ remained constant (Figure 2C), although the phosphorylation of

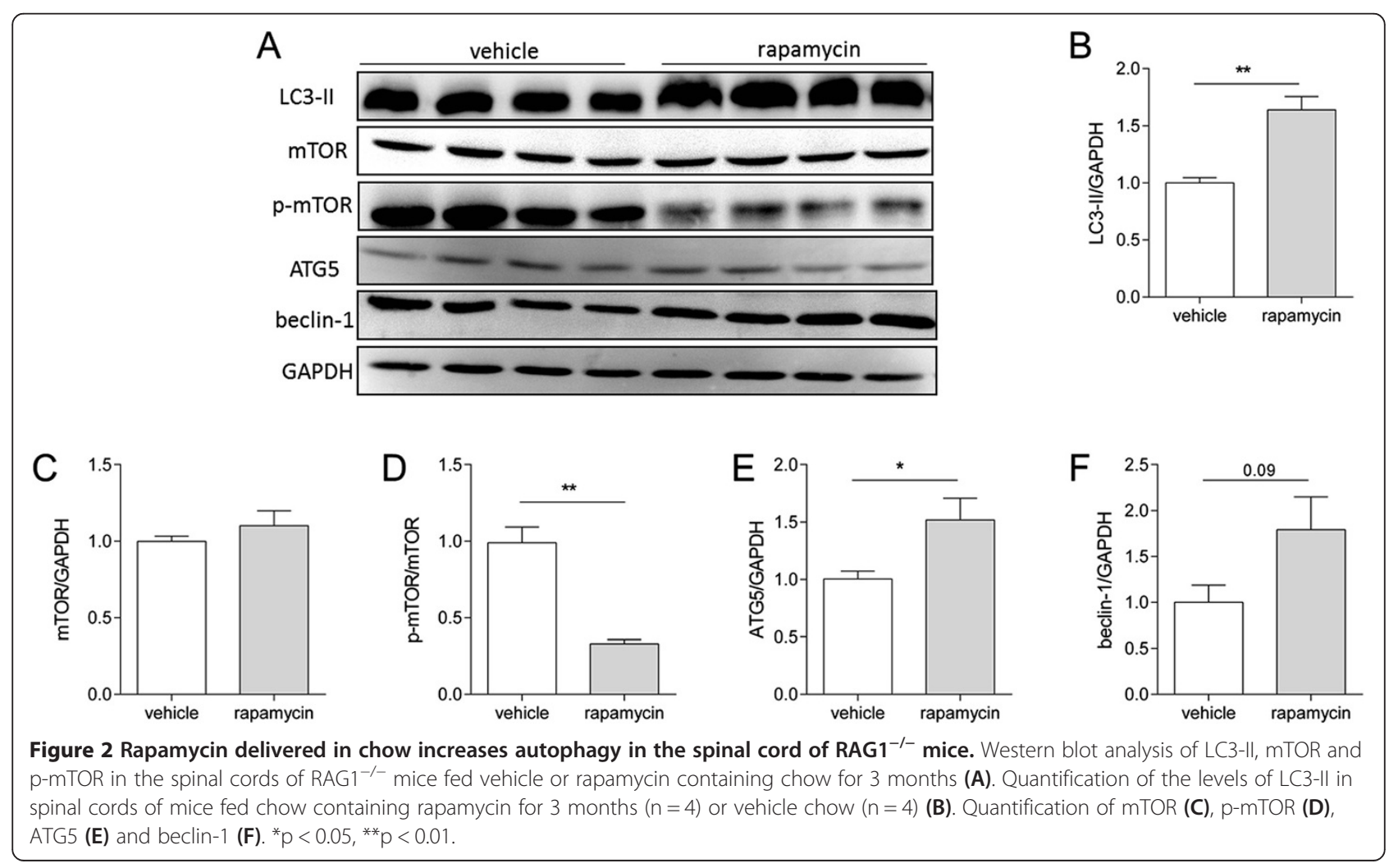


the receptor was decreased by rapamycin (Figure 2D). Additional markers of autophagy, ATG5 and beclin-1, are also increased by rapamycin (Figure $2 \mathrm{E} \& \mathrm{~F}$ ).

To assess the effect of increased autophagy in ALS, we treated pre-symptomatic SOD ${ }^{\mathrm{G} 93 \mathrm{~A}}$ mice with rapamycin. Rapamycin does not affect disease onset (Figure 3B), disease duration (Figure $3 \mathrm{C}$ ) or survival of SOD $1^{\mathrm{G} 93 \mathrm{~A}}$ mice compared to SOD $1^{\text {G93A }}$ mice fed vehicle diet (Figure 3D). However, a potential protective effect of increased autophagy by rapamycin in $\mathrm{SOD} 1^{\mathrm{G} 93 \mathrm{~A}}$ mice may be masked by the detrimental immunosuppressive effect of rapamycin on lymphocytes in SOD1 ${ }^{\mathrm{G} 93 \mathrm{~A}}$ mice. To circumvent this effect of rapamycin, we crossbred $\mathrm{RAG}^{-1-}$ mice, which are devoid of mature lymphocytes [22], with SOD1 ${ }^{\text {G93A }}$ mice to assess the effect of rapamycin in the absence of mature lymphocytes. Interestingly, when the immunosuppressive effect of rapamycin on lymphocytes cannot be exerted (as is the case in $\mathrm{RAG}^{-/-}$mice), rapamycin significantly prolongs disease duration (Figure $3 G$ ) and survival with 6.5 days (Figure $3 \mathrm{H}$ ), while it does not affect disease onset (Figure 3F). Despite that ALS mice may consume less chow as they approach end stage, a trend is shown for increased autophagy in the spinal cords of $\mathrm{RAG}^{-/-} \mathrm{SOD} 1^{\mathrm{G} 93 \mathrm{~A}}$ mice on rapamycincontaining chow (Figure 3I-L). Additionally, RAG1 ${ }^{-/}$ SOD $1^{\mathrm{G} 93 \mathrm{~A}}$ mice fed rapamycin-containing chow have a similar amount of neurons in the spinal cord at end stage (Figure 3M), suggesting these mice did not become end stage due to other reasons than neuronal loss.

The slight increase of survival of $\mathrm{RAG}^{-/-} \mathrm{SOD} 1^{\mathrm{G} 93 \mathrm{~A}}$ mice fed rapamycin-containing chow implies that the beneficial effect of increasing autophagy in SOD1 ${ }^{\text {G93A }}$ mice may be masked by the immunosuppressive effect of rapamycin in mice with mature lymphocytes. In line with this hypothesis, a recent study that assessed the effect of rapamycin on ALS mice showed a decreased survival of more than 2 weeks [6]. This is comparable to the size of the effect on survival detected by others after removing mature lymphocytes from ALS mice [23]. In our mice, the survival of vehicle treated SOD $1^{\mathrm{G} 93 \mathrm{~A}}$ and $\mathrm{RAG}^{-/-} \mathrm{SOD} 1^{\mathrm{G} 93 \mathrm{~A}}$ mice do not significantly differ ( $\mathrm{p}=$ 0.20 ), although there is a trend that $\mathrm{RAG}^{-/-} \mathrm{SOD} 1^{\mathrm{G} 93 \mathrm{~A}}$ mice live slightly shorter (4.0 days).

The dual effect of rapamycin (immunosuppression and increased autophagy) is a contraindication to use this drug for ALS patients and thus the development of

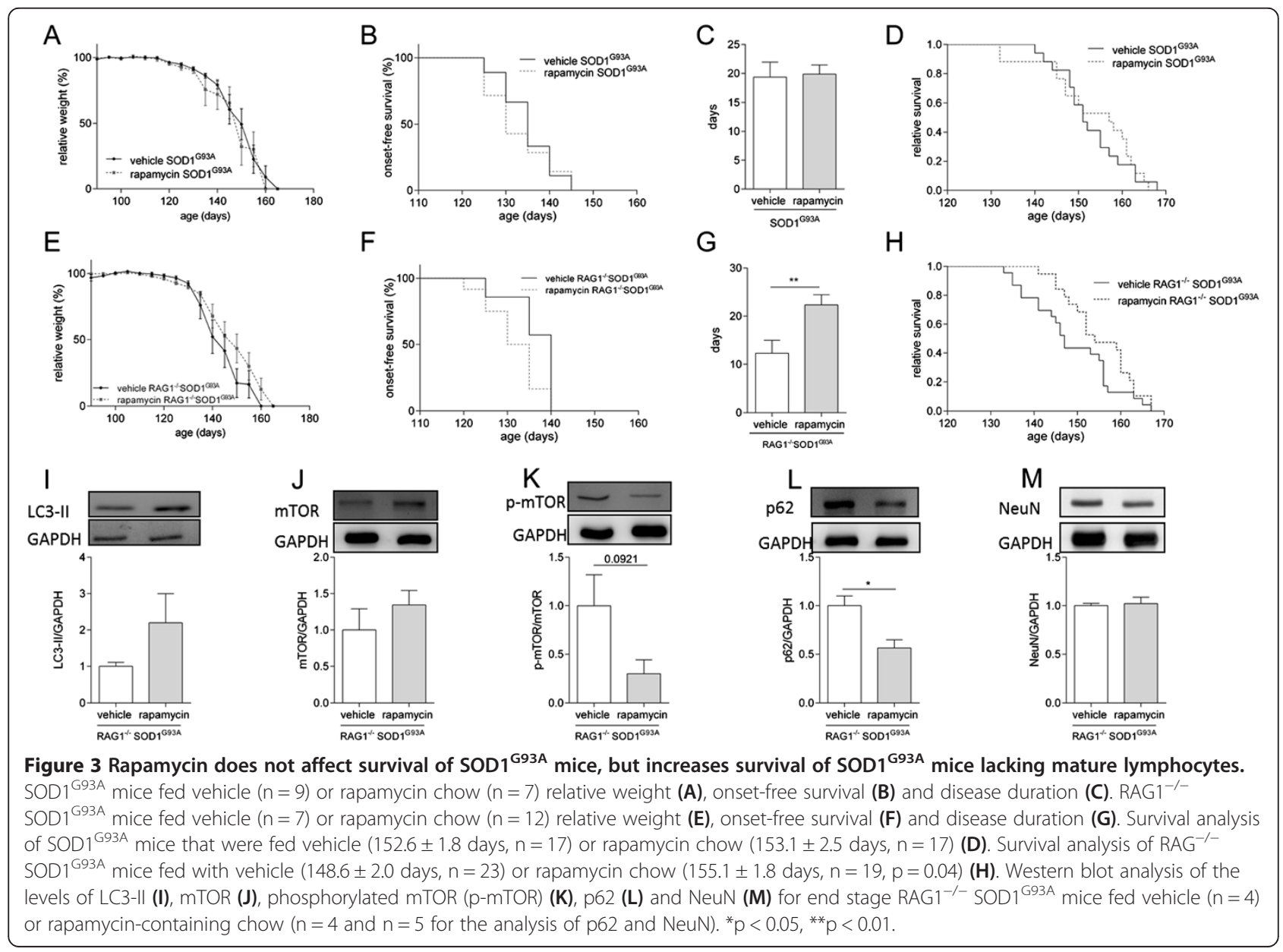


compounds that specifically target autophagy without immunosuppression is essential. As removing T-cells may be detrimental in ALS, RAG1 ${ }^{-1-}$ mice are useful to assess the role of autophagy in different disease models, such as in inclusion body myopathy [24], until specific autophagy-inducing compounds become available.

In summary, a protective effect of increasing autophagy is expected in ALS, but not yet been demonstrated pharmacologically in vivo. We circumvented the negative effect of rapamycin on lymphocytes by removing these cells from SOD $1^{\text {G93A }}$ mice and found a moderate but significant effect on survival. This protective effect seems to be due to increased autophagy and indicates that this could become a therapeutic strategy to treat ALS.

\section{Methods}

\section{Animal testing}

Mice overexpressing SOD $1^{\mathrm{G} 93 \mathrm{~A}}$ and recombination activating gene 1 knockout ( $\mathrm{RAG}^{-/-}$) mice were purchased from Jackson Laboratories (Bar Harbor, USA) and maintained on a C57BL/6 background. Chow and water were provided ad libitum and mice were housed in the specific pathogen free facility of KU Leuven. A decrease of $10 \%$ in body weight compared to their average between day 90 and 105 is considered as disease onset. Mice no longer surviving were assessed as $0 \mathrm{~g}$. End stage is defined as the age when mice could no longer right themselves from their back within $10 \mathrm{~s}$ and this is the measurement of survival. For Figure $3 \mathrm{~A}-\mathrm{E}$ both $\mathrm{RAG} 1^{+/-}$ SOD $1^{\mathrm{G} 93 \mathrm{~A}}$ and $\mathrm{RAG} 1^{+/+}$SOD $1^{\mathrm{G} 93 \mathrm{~A}}$ mice were used, as their survival does not differ. All experiments were performed with the approval of the Animal Ethical Committee of KU Leuven (P020/2010).

\section{Diet preparation}

Rapamycin (LC Labs) was encapsulated by Southwest Research Institute (San Antonio, USA) with coating material Eudragit S100 (Röhm Pharma) as described previously [25]. Encapsulated rapamycin was processed in Purina 5LG6 mouse chow by TestDiet (London, UK) at a concentration of $14 \mathrm{mg} / \mathrm{kg}$ food $(2.33 \mathrm{mg}$ of rapamycin per $\mathrm{kg}$ body weight per day, assuming a body weight of $30 \mathrm{~g}$ and a daily consumption of $5 \mathrm{~g}$ per mouse). Rapamycin or vehicle chow substituted the animal house chow ad libitum from 60 days of age until end stage or 160 days.

\section{Western blot}

Samples were size-separated through denaturing sodium dodecyl sulfate polyacrylamide gel electrophoresis. Protein was electro-transferred to a nitrocellulose membrane in Tris-glycine-methanol buffer and processed with the Supersignal ChemiLuminiscence detection kit
(Pierce Biotechnology Inc.). The following antibodies were used: anti LC3-II, anti mTOR, anti p-mTOR, anti Beclin, anti ATG5 and anti p-62 (Cell Signalling).

\section{Statistical analysis}

The statistical analysis was performed with Graphpad Prism (version 5.04) software. Unpaired 2-sided Student's t-tests were used to analyse differences between 2 groups and the Gehan-Breslow-Wilcoxon for survival data. Significance is assumed for $\mathrm{p} \leq 0.05$. Values are shown as mean \pm standard error of the mean.

\section{Abbreviations}

ALS: Amyotrophic lateral sclerosis; ATG5: Autophagy protein 5;

LC3: Microtubule-associated proteins 1A/1B light chain; mTOR: Mammalian target of rapamycin; p-mTOR: Phosphorylated form of the mammalian target of rapamycin; NeuN: Neuronal nuclear antigen (Feminizing Locus on X-3); SOD1: Superoxide dismutase 1.

\section{Competing interests}

The authors declare that they have no competing interests.

\section{Authors' contributions}

KAS, SS and JD performed the murine behavioural experiments. SH and ABA performed the Western blot analysis. KAS, PVD, WR, AL and LVDB participated in the design of the study. KAS and LVDB participated in preparation of the manuscript. All authors read and approved the final manuscript.

\section{Acknowledgements}

We thank Elizabeth Fernandez (University of Texas Health Science Center Barshop, Institute for Longevity and Aging Studies) and Carrie Schultz (Land $\mathrm{O}^{\prime}$ Lakes Purina Feed) for their help in obtaining the rapamycin and eudragit diets. In addition, we thank Lawrence Van Helleputte and Nancy Florenty for technical support. This work was supported by grants from the "Fund for Scientific Research Flanders" (FWO-Vlaanderen), the University of Leuven (KU Leuven), the European Community's Health Seventh Framework Programme (FP7/2007-2013) under grant agreement number 259867 and the Belgian Government (Interuniversity Attraction Poles, programme P7/16) of the Belgian Federal Science Policy Office. PVD holds a clinical investigatorship of FWO-Vlaanderen. WR is supported by the E. von Behring Chair for

Neuromuscular and Neurodegenerative Disorders.

\section{Author details}

${ }^{1}$ Laboratory of Neurobiology, Vesalius Research Center, VIB, Leuven, Belgium. 2Experimental Neurology (Department of Neurosciences), Leuven Research Institute for Neuroscience and Disease (LIND), University of Leuven (KU Leuven), Leuven, Belgium. ${ }^{3}$ Autoimmune Genetics Laboratory, VIB, Leuven, Belgium. ${ }^{4}$ Department of Microbiology and Immunology, University of Leuven (KU Leuven), Leuven, Belgium. ${ }^{5}$ Department of Neurology, University Hospitals Leuven, Leuven, Belgium.

Received: 16 April 2013 Accepted: 4 September 2013

Published: 11 September 2013

\section{References}

1. Logroscino G, Traynor BJ, Hardiman O, Chio A, Mitchell D, Swingler RJ, Millul A, Benn E, Beghi E: Incidence of amyotrophic lateral sclerosis in Europe. J Neurol Neurosurg Psychiatry 2010, 81:385-390.

2. Julien JP, Kriz J: Transgenic mouse models of amyotrophic lateral sclerosis. Biochim Biophys Acta 2006, 1762:1013-1024.

3. Ticozzi N, Ratti A, Silani V: Protein aggregation and defective RNA metabolism as mechanisms for motor neuron damage. CNS Neurol Disord Drug Targets 2010, 9:285-296.

4. Ido A, Fukuyama H, Urushitani M: Protein misdirection inside and outside motor neurons in amyotrophic lateral sclerosis (ALS): a possible clue for therapeutic strategies. Int J Mol Sci 2011, 12:6980-7003. 
5. Shen X, Ying H, Qiu Y, Park JS, Shyam R, Chi ZL, Iwata T, Yue BY: Processing of optineurin in neuronal cells. J Biol Chem 2011, 286:3618-3629.

6. Miyakawa T, Maeda A, Yamazawa T, Hirose K, Kurosaki T, lino M: Encoding of $\mathrm{Ca} 2+$ signals by differential expression of IP3 receptor subtypes. EMBO J 1999, 18:1303-1308.

7. Tian F, Morimoto N, Liu W, Ohta Y, Deguchi K, Miyazaki K, Abe K: In vivo optical imaging of motor neuron autophagy in a mouse model of amyotrophic lateral sclerosis. Autophagy 2011, 7:985-992.

8. Morimoto N, Nagai M, Ohta Y, Miyazaki K, Kurata T, Morimoto M, Murakami $T$, Takehisa $Y$, Ikeda $Y$, Kamiya T, Abe K: Increased autophagy in transgenic mice with a G93A mutant SOD1 gene. Brain Res 2007, 1167:112-117.

9. Sasaki S: Autophagy in spinal cord motor neurons in sporadic amyotrophic lateral sclerosis. J Neuropathol Exp Neurol 2011, 70:349-359.

10. Spencer B, Potkar R, Trejo M, Rockenstein E, Patrick C, Gindi R, Adame A, Wyss-Coray T, Masliah E: Beclin 1 gene transfer activates autophagy and ameliorates the neurodegenerative pathology in alpha-synuclein models of Parkinson's and Lewy body diseases. J Neurosci 2009, 29:13578-13588.

11. Menzies FM, Huebener J, Renna M, Bonin M, Riess O, Rubinsztein DC: Autophagy induction reduces mutant ataxin-3 levels and toxicity in a mouse model of spinocerebellar ataxia type 3. Brain 2010, 133:93-104.

12. Ravikumar B, Vacher C, Berger Z, Davies JE, Luo S, Oroz LG, Scaravilli F, Easton DF, Duden R, O'Kane CJ, Rubinsztein DC: Inhibition of mTOR induces autophagy and reduces toxicity of polyglutamine expansions in fly and mouse models of Huntington disease. Nat Genet 2004, 36:585-595.

13. Wang IF, Guo BS, Liu YC, Wu CC, Yang CH, Tsai KJ, Shen CK: Autophagy activators rescue and alleviate pathogenesis of a mouse model with proteinopathies of the TAR DNA-binding protein 43. Proc Natl Acad Sci USA 2012, 109:15024-15029.

14. Hetz C, Thielen P, Matus S, Nassif M, Court F, Kiffin R, Martinez G, Cuervo AM, Brown RH, Glimcher LH: XBP-1 deficiency in the nervous system protects against amyotrophic lateral sclerosis by increasing autophagy. Genes Dev 2009, 23:2294-2306.

15. Heitman J, Movva NR, Hall MN: Targets for cell cycle arrest by the immunosuppressant rapamycin in yeast. Science 1991, 253:905-909.

16. Bhattacharya A, Bokov A, Muller FL, Jernigan AL, Maslin K, Diaz V, Richardson A, Van Remmen H: Dietary restriction but not rapamycin extends disease onset and survival of the $\mathrm{H} 46 \mathrm{R} / \mathrm{H} 48 \mathrm{Q}$ mouse model of ALS. Neurobiol Aging 2012, 33:1829-1832.

17. Thomson AW, Turnquist HR, Raimondi G: Immunoregulatory functions of mTOR inhibition. Nat Rev Immunol 2009, 9:324-337.

18. Chiu IM, Chen A, Zheng Y, Kosaras B, Tsiftsoglou SA, Vartanian TK, Brown RH $\mathrm{Jr}$, Carroll MC: T lymphocytes potentiate endogenous neuroprotective inflammation in a mouse model of ALS. Proc Natl Acad Sci USA 2008, 105:17913-17918.

19. Beers DR, Henkel JS, Zhao W, Wang J, Appel SH: CD4+ T cells support glial neuroprotection, slow disease progression, and modify glial morphology in an animal model of inherited ALS. Proc Natl Acad Sci USA 2008, 105:15558-15563.

20. Patel BP, Hamadeh MJ: Nutritional and exercise-based interventions in the treatment of amyotrophic lateral sclerosis. Clin Nutr 2009, 28:604-617.

21. Speakman JR, Mitchell SE: Caloric restriction. Mol Aspects Med 2011, 32:159-221.

22. Mombaerts $P$, lacomini J, Johnson RS, Herrup K, Tonegawa S, Papaioannou VE: RAG-1-deficient mice have no mature B and T lymphocytes. Cell 1992, 68:869-877.

23. Beers DR, Henkel JS, Zhao W, Wang J, Huang A, Wen S, Liao B, Appel SH: Endogenous regulatory $T$ lymphocytes ameliorate amyotrophic lateral sclerosis in mice and correlate with disease progression in patients with amyotrophic lateral sclerosis. Brain 2011, 134:1293-1314.

24. Ching JK, Elizabeth SV, Ju JS, Lusk C, Pittman SK, Weihl CC: mTOR dysfunction contributes to vacuolar pathology and weakness in valosincontaining protein associated inclusion body myopathy. Hum Mol Genet 2013, 22:1167-1179.

25. Harrison DE, Strong R, Sharp ZD, Nelson JF, Astle CM, Flurkey K, Nadon NL, Wilkinson JE, Frenkel K, Carter CS, et al: Rapamycin fed late in life extends lifespan in genetically heterogeneous mice. Nature 2009, 460:392-395.

doi:10.1186/1750-1326-8-31

Cite this article as: Staats et al:: Rapamycin increases survival in ALS mice lacking mature lymphocytes. Molecular Neurodegeneration 2013 8:31.

\section{Submit your next manuscript to BioMed Central and take full advantage of:}

- Convenient online submission

- Thorough peer review

- No space constraints or color figure charges

- Immediate publication on acceptance

- Inclusion in PubMed, CAS, Scopus and Google Scholar

- Research which is freely available for redistribution 